\title{
Non-uniform PSC occurrence within the Arctic polar vortex
}

\author{
Marion Müller, Roland Neuber, and Georg Beyerle ${ }^{1}$ \\ Alfred Wegener Institute Foundation for Polar and Marine Research, Potsdam, Germany \\ E. Kyrö and R. Kivi \\ Finnish Meteorological Institute, Arctic Research Centre, Sodankylä, Finland
}

L. Wöste

Free University Berlin, Physics Department, Berlin, Germany

\begin{abstract}
A multi-year dataset of lidar measurements of polar stratospheric clouds (PSCs) from two sites in the Arctic (Sodankylä, $67^{\circ} \mathrm{N}, 27^{\circ} \mathrm{E}$, and $\mathrm{Ny}-\AA$ Ålesund, $79^{\circ} \mathrm{N}, 12^{\circ} \mathrm{E}$ ) has been analyzed with respect to the existence temperature of different PSC types. Due to the location of the measurement sites relative to the polar vortex, their observations are most of the time representative of vortex edge and vortex center conditions, respectively. The comparison of the aerosol lidar measurements with local and trajectory temperatures reveals that PSC occurrence is favored at the edge of the Arctic polar vortex. One possibility discussed here is a differential distribution of water vapor that could be responsible for the non-uniform threshold temperatures and thus differential PSC occurrence within the polar vortex.
\end{abstract}

\section{Introduction}

Below a certain threshold temperature, polar stratospheric clouds (PSCs) can form and hence provide the surface for heterogeneous reactions that lead to the activation of initially bound chemical reservoir species. Thus, PSCs are a main factor for the springtime stratospheric ozone loss in the polar regions [e.g. Solomon et al., 1999].

Different PSC types can be distinguished by their particle composition. While PSCs of type Ia consist of solid nitric acid trihydrate (NAT) particles [Voigt et al., 2000], PSC of type Ib are made up from liquid ternary $\mathrm{H}_{2} \mathrm{O} / \mathrm{HNO}_{3} / \mathrm{H}_{2} \mathrm{SO}_{4}$ solution (STS) droplets [Schreiner et al., 1999]. Below the frost point, water ice particles form PSC type II. Typically, 5 ppmv $\mathrm{H}_{2} \mathrm{O}$ and 9-10 ppbv $\mathrm{HNO}_{3}$ are assumed as trace gas input for the calculation of PSC threshold temperatures [Koop et al., 1997; Tabazadeh et al., 2001].

Stratospheric ozone loss in the polar regions is crucially enhanced by the effects of denitrification and dehydration resulting from the formation and subsequent sedimentation of large PSC particles. Therefore, the potential occurrence of PSC II in the
Arctic is of particular importance. Remarkably, the observations of PSCs II in Sodankylä are very dissimilar from the observations in Ny-Ålesund. Here, we present a comparison focussing on the difference in PSC observations at the two arctic lidar stations in relation to the polar vortex position.

\section{Instrumentation}

The PSC lidar measurements presented here were performed in Sodankylä, Finland $\left(67^{\circ} \mathrm{N}, 27^{\circ} \mathrm{E}\right)$, and Ny-Ålesund, Spitsbergen $\left(79^{\circ} \mathrm{N}, 12^{\circ} \mathrm{E}\right)$.

The aerosol lidar data from both sites reach back until winter 1991/1992. In this study, we refer to the Sodankylä aerosol lidar that was operative during the Stratospheric Aerosols and Ozone in the Northern and Southern Hemisphere (SAONAS) campaign in winters 1996/1997 to $1998 / 1999$, and our case study on PSC type I occurrence at both stations is limited to this period.

Both aerosol lidar systems are multiwavelength instruments with equivalent sending and detection units. For a detailed description of the instrument parameters see Stein et al. [1999] for Sodankylä and Biele et al. [2001] for Ny-Ålesund. In the context of this PSC study, data are restricted to measurements 
with the wavelength $\lambda=532 \mathrm{~nm}$ in the parallel and perpendicular polarization plane. From these measurements it is possible to retrieve the PSC backscatter ratio as well as the volume depolarization, leading to the determination of different PSC types and their temporal and spatial evolution. In case of Sodankylä, also measurements at $\lambda=1064 \mathrm{~nm}$ (non-polarized) are included.

At both stations, the acquisition of at least one vertical temperature profile per day is ensured by meteorological radiosondes.

\section{Observations}

Both in Sodankylä and Ny-Ålesund, long-term observations revealed the common existence of PSCs consisting of liquid and / or solid particles [Stein et al., 1999; Rex et al., 2000]. In general, the detected PSC events occurred in good agreement with the parallel temperature measurements. Yet, discrepancies between PSC occurrence and existence temperature have been observed in several cases.

\subsection{PSC II Occurrence in Sodankylä}

In Sodankylä, several PSCs II have been observed during the mentioned observation period: on January $22 / 23$, 1997, on December 16, 1997, and on December 2, 1998. Although on all occasions the synoptic temperature was above the frost point assuming 5 ppmv water vapor $\left(\mathrm{T}_{\text {ICE[5ppmv }]}\right)$, water ice PSCs were able to develop due to local cooling in stratospheric lee waves induced at the Scandinavian mountain ridge [Dörnbrack et al., 1999; Dörnbrack and Leutbecher, 2001].

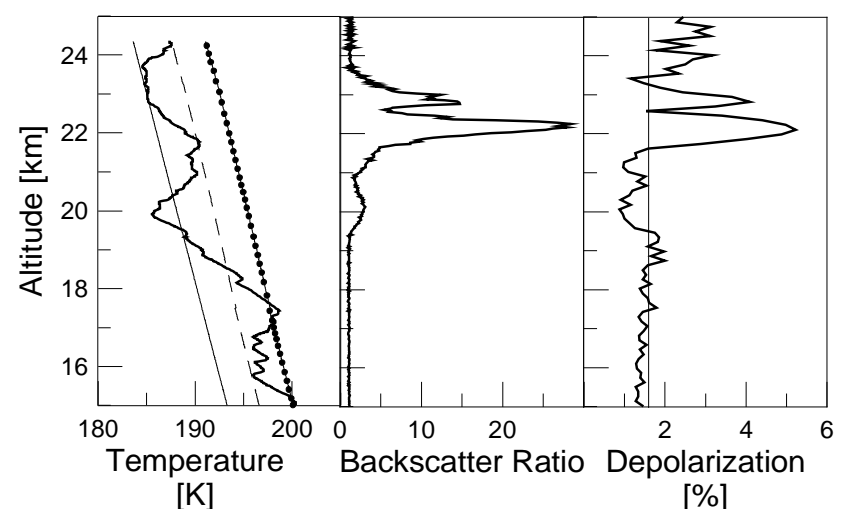

Figure 1. Sodankylä, Dec.16, 1997. left: 11:00 UTC radiosonde temperature profile (bold line) with the 5 ppmv $\mathrm{H}_{2} \mathrm{O}$ threshold temperatures for NAT (dotted line), STS (dashed line) and ice (thin line). center: lidar backscatter ratio at $532 \mathrm{~nm}$, averaged between 04:00 and 05:00 UTC. right: lidar volume depolarization at $532 \mathrm{~nm}$ (bold line) with volume depolarization of pure air (thin line) for reference.
The influence of lee wave activity on the temperature distribution is found e.g. in the Sodankylä radiosonde profile on December 16, 1997, shown in Figure 1. The wavelike structured temperature profile shows cold deviations below $\mathrm{T}_{\text {ICE[5ppmv] }}$, but also warmer inversion layers. Even if the temperature drops only below the STS threshold, a PSC II is observed between 20.5 and $22.5 \mathrm{~km}$ altitude. The identification of the water ice PSC is based on the very high backscatter ratio of about $\mathrm{R}=30$ and the large volume depolarization. Apart from the described lee wave induced water ice PSCs, also synoptic scale PSCs II have been observed in Sodankylä (Vömel et al., 1997; Kivi et al., 2001).

\subsection{No PSC II Occurrence in $\mathrm{Ny}$-Ålesund}

The Ny-Ålesund measurements exhibit a different discrepancy between local temperature and PSC observation: while on several days the local radiosonde temperatures were well below the frost point $\mathrm{T}_{\mathrm{ICE}[5 \mathrm{ppmv}]}$, the simultaneous lidar measurements did not detect any PSC II. For instance, on the basis of the Ny-Ålesund radiosonde temperature profile of Jan. 17, 1996 (Figure 2), the occurrence of a PSC II should be expected above $23 \mathrm{~km}$, but only a PSC Ib was detected by the aerosol lidar. The lidar backscatter ratio was enhanced to about $\mathrm{R}=3.5$ with a low volume depolarization that indicates spherical particles and hence liquid droplets. The existence of water ice particles can be ruled out. Similar cases are found on ten days in different winters and so far, PSCs II have only been detected once in Ny-Ålesund by Shibata et al. [1999].

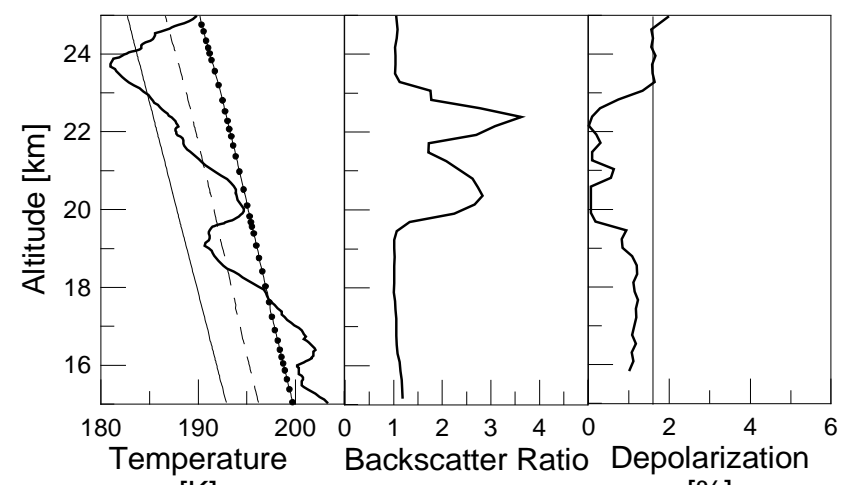

$[\mathrm{K}]$

[\%]

Figure 2. Ny-Ålesund, Jan.17, 1996. left: 21:00 UTC radiosonde temperature profile (bold line) with the 5 ppmv $\mathrm{H}_{2} \mathrm{O}$ threshold temperatures for NAT (dotted line), STS (dashed line) and ice (thin line). center: lidar backscatter ratio at $532 \mathrm{~nm}$, averaged between 23:00 and 00:00 UTC. right: lidar volume depolarization at $532 \mathrm{~nm}$ (bold line) with volume depolarization of pure air (thin line) for reference. 


\subsection{PSC I Occurrence at Both Stations}

Likewise, the observed PSCs of type I at Ny-Ålesund and Sodankylä do not similarly occur below the NAT threshold temperature assuming 5 ppmv water vapor $\left(\mathrm{T}_{\mathrm{NAT}[5 \mathrm{ppmv}]}\right)$ at both stations.

On the one hand, PSCs have been observed in Sodankylä at temperatures above $\mathrm{T}_{\mathrm{NAT}[5 \mathrm{ppmv}]}$ on a few days. As in the case of the observed water ice PSCs, the most obvious explanation may be an influence of possible mesoscale temperature fluctuations by mountain wave activity. Still, if all measurements during possible mountain wave activity in the Sodankylä region are rejected according to Dörnbrack et al. [2001], PSCs are detected above $\mathrm{T}_{\mathrm{NAT}[5 \mathrm{ppmv}]}$ on January 4 (Figure 3 a) and January 12, 1997. In these cases, earlier particle formation due to possible mesoscale temperature fluctuations above e.g. Greenland may be neglected as the temperatures were well above $\mathrm{T}_{\mathrm{NAT}[5 \mathrm{ppm}]}$ along the backtrajectories.

Apart from solid particles interpreted as sulfuric acid tetrahydrate (SAT) [Beyerle et al., 2001], all PSC events in Ny-Ålesund have been observed below $\mathrm{T}_{\mathrm{NAT}[5 \mathrm{ppmv}]}$ without exception. Remarkably, on 9 days the lidar in Ny-Ålesund detected a PSC free stratosphere, although the radiosonde temperature was well below $\mathrm{T}_{\mathrm{NAT}[5 \mathrm{ppmv}]}$ or even below $\mathrm{T}_{\mathrm{STS}[5 \mathrm{ppm}]}$ (the threshold temperature for STS assuming $5 \mathrm{ppmv}$ water vapor). Six of these days fall into the period January and February 1997 (Jan.12, Jan. 16, Jan. 17, Jan. 23, Feb. 5, Feb. 8), while the other days were Feb. 23 and Feb. 29, 1996, as well as Jan. 24, 1998.

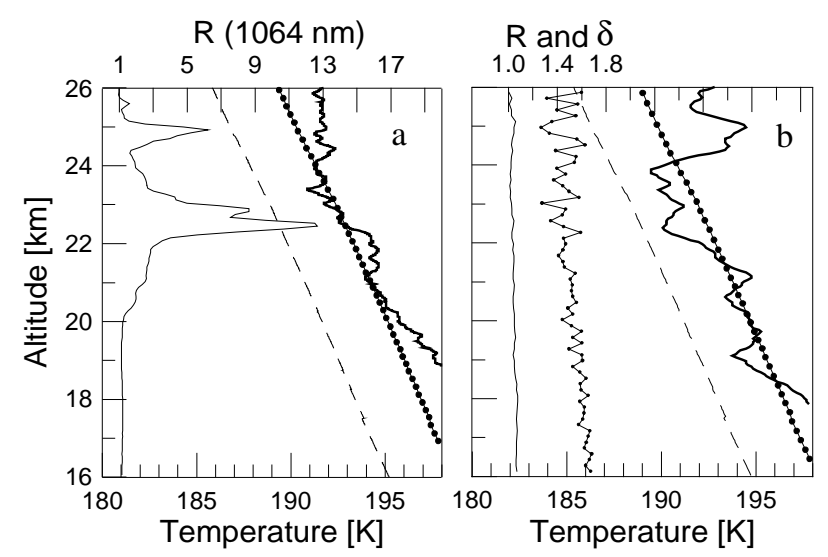

Figure 3. (a): Sodankylä, Jan. 4, 1997. Backscatter ratio at $\lambda=1064 \mathrm{~nm}$, 1-hour-mean between 15:09 and 16:10 UTC (thin line), with the 11:00 UTC radiosonde temperature (bold line) as well as $\mathrm{T}_{\mathrm{NAT}[5 \mathrm{ppm}]}$ (dotted line) and $\mathrm{T}_{\mathrm{STS}[5 \mathrm{ppmv}]}$ (dashed line). (b): Ny-Ålesund, Jan.12, 1997. Backscatter ratio (thin line) and volume depolarization $\delta$ (thin line with dots) at $\lambda=532 \mathrm{~nm}$, 1-hour-mean between 10:05 and 11:02 UTC, together with the 11:00 UTC radiosonde temperature (bold line) as well as $\mathrm{T}_{\mathrm{NAT}[5 \mathrm{ppmv}]}$ (dotted line) and $\mathrm{T}_{\mathrm{STS}[5 \mathrm{ppmv}]}$ (dashed line) for reference.
Out of the large set of lidar measurements, only these days with radiosonde temperatures lower than $\mathrm{T}_{\mathrm{NAT}[5 \mathrm{ppmv}]}-1 \mathrm{~K}$ in Ny-Ålesund are taken into account. Other restrictions are: the temperature along the backtrajectories is below $\mathrm{T}_{\mathrm{NAT}[5 \mathrm{ppm}]}$ for at least 12 hours, and a completely cloud free stratosphere above Ny-Ålesund. One example is displayed in Figure 3 b, showing the profiles of temperature, backscatter ratio, and volume depolarization on January 12, 1997.

Altogether, the described observations lead to the conclusion that PSC existence is favored above Sodankylä compared to Ny-Ålesund.

\section{Discussion}

The main difference between the two stations is their position relative to the polar vortex. While the vortex is centered above Spitsbergen during most of the Arctic winter, the vortex edge is usually situated above Scandinavia. From the observations described above, it is apparent that the vortex edge is the region of favored PSC existence.

The vortex edge usually covers several source regions for mountain waves. In addition, the wind conditions near the vortex edge forward the stratospheric wave propagation. Thus, mesoscale temperature fluctuations and additional PSC formation are found at the vortex edge, explaining the described PSC observations in Sodankylä.

Nevertheless, as PSC formation depends on the temperature to drop below a certain threshold temperature, it is also possible that a local change in the threshold temperatures leads to the observed PSC occurrence. The most distinct change in threshold temperatures is induced by a change of the water vapor mixing ratio. An increase (decrease) of $1 \mathrm{ppmv}$ $\mathrm{H}_{2} \mathrm{O}$ results in an increase (decrease) of $1 \mathrm{~K}$ for $\mathrm{T}_{\text {ICE }}$ [Marti and Mauersberger, 1993] and about 0.8 K for $\mathrm{T}_{\mathrm{NAT}}$ [Hanson and Mauersberger, 1988].

The general non-existence of PSCs II in Ny-Ålesund as well as the absence of PSC I below $\mathrm{T}_{\mathrm{NAT}[5 \mathrm{ppm} \text { v }}$ can potentially be attributed to a lower $\mathrm{H}_{2} \mathrm{O}$ mixing ratio and thereupon lower threshold temperatures. Any significant dehydration and ice particle sedimentation is linked to the existence of PSCs II and has so far only been observed in single events in the Arctic [Vömel et al., 1997; Stowasser et al., 1999]. Nevertheless, it has to be considered that dehydration may occur to a small extent in the Arctic stratosphere. In the context of our PSC observations, dehydration may have a small effect in some cases for the nonexisting PSCs in Ny-Ålesund, but at the same time there is no evidence for an influence of dehydration on the existence of PSC I in Sodankylä. 
The non-uniform PSC occurrence inside the polar vortex would also be generated if the water vapor mixing ratio was higher in the vortex edge region than in the vortex center. In the winter polar stratosphere, water vapor behaves as a conserved tracer as neither photo-dissociation of $\mathrm{H}_{2} \mathrm{O}$ nor photooxidation of methane occurs [Seele and Hartogh, 2000]. Consequently, stratospheric $\mathrm{H}_{2} \mathrm{O}$ is transported according to the global circulation, with strong descent above the winter pole. However, the strongest descent takes place at the edge of the polar vortex rather than in the center [Pierce et al., 1994; Manney et al., 1999]. Thus, maximum water vapor mixing ratios and highest PSC threshold temperatures can be expected to occur in the vortex edge region and accordingly above Sodankylä. Indeed, for higher altitudes $(\sim 35 \mathrm{~km})$ a ring of maximum water vapor mixing ratio inside the Arctic polar vortex has been observed by the Microwave Limb Sounder (MLS) [Lahoz et al., 1994]. The presumed water vapor gradient within the polar vortex results in a ring with favorable PSC conditions along the vortex edge region. At the same time, the conditions for PSC existence are fulfilled less frequent in the center of the vortex due to the weaker descent of $\mathrm{H}_{2} \mathrm{O}$ from the upper stratosphere. On that account, the formation of water ice particles becomes more difficult, explaining the general non-existence of PSC II above Ny-Ålesund. However, a water ice PSC has once been observed above Ny-Ålesund by the Japanese aerosol lidar [Shibata et al., 1999], yet in this case the vortex edge was located above the station.

Quantitative, a reduction of 2.5 ppmv $\mathrm{H}_{2} \mathrm{O}$ on January 12, 1997, in Ny-Ålesund and the resulting shift of the PSC threshold to lower temperatures would explain the observations shown in Figure $3 \mathrm{~b}$. In return, additional $1.5 \mathrm{ppmv} \mathrm{H}_{2} \mathrm{O}$ on January 4, 1997, in Sodankylä would increase the PSC threshold to higher temperatures and thus explain the observed PSC in Figure 3a. Compared to in situ measurements of stratospheric water vapor [Ovarlez and Ovarlez, 1994; Stowasser et al., 1999], the necessary differences in the water vapor mixing ratio may be too large to be solely responsible for the observed non-uniform PSC occurrence. Still, the distribution of stratospheric water vapor can be the main effect leading to the observed spatial PSC distribution.

Regarding the observations of PSC type I, the idea of a stratospheric polar freezing belt introduced by Tabazadeh et al. [2001] also supports favorable PSC conditions at the vortex edge.

\section{Summary}

Stratospheric aerosol lidar observations at two Arctic stations, Sodankylä and Ny-Ålesund, have revealed that PSC occurrence is favored at the edge of the vortex compared to the vortex centre.

As the vortex edge often covers the source regions for mountain waves and provides the necessary wind conditions for wave propagation, it is a location of mesoscale temperature fluctuations and additional PSC formation. Still, other mechanisms may lead to the observed non-uniform PSC occurrence. The generally adopted threshold temperatures are based on the assumption of 5 ppmv stratospheric $\mathrm{H}_{2} \mathrm{O}$. As small changes in water vapor have a large influence on the saturation temperature of PSC particles, a gradiently distribution of $\mathrm{H}_{2} \mathrm{O}$ within the polar vortex leads likewise to a non-uniform threshold temperature. Due to uneven descent of air inside the polar vortex, more water vapor and thus higher PSC threshold temperatures are potentially found at the vortex edge, corresponding to the observed favored PSC existence. Similarly, a lower $\mathrm{H}_{2} \mathrm{O}$ mixing ratio due to lower subsidence in the center of the vortex may affect the formation of water ice PSCs in Ny-Ålesund.

Acknowledgments. We like to thank the station teams at Koldewey station in Ny-Ålesund for their diligent radiosonde and lidar data acquisition, as well as J.Biele for parts of the evaluation and B.Stein for helpful discussions. We also wish to express our great thanks to the science team in Sodankylä. The very constructive comments of one reviewer are gratefully acknowledged. This work was in part funded through the European Commission project EVK2-2000-00707 (MAPSCORE).

\section{References}

Beyerle, G., H. Deckelmann, R. Neuber, J. M. Rosen, E. Reimer, M. R. Schoeberl: Occurrence of solid particles in the winter polar stratosphere above nitric acid trihydrate coexistence temperature inferred from ground-based polarization lidar observations at Ny-Ålesund, Spitsbergen. J. Geophys. Res., 106, 2979-2992, 2001.

Biele, J., A. Tsias, B. P. Luo, K. S. Carslaw, R. Neuber, G. Beyerle, T. Peter: Non-equilibrium coexistence of solid and liquid particles in Arctic stratospheric clouds. J. Geophys. Res., in print, 2001.

Dörnbrack, A., M. Leutbecher, R. Kivi, E. Kyrö: Mountain wave induced record low stratospheric temperatures above Northern Scandinavia. Tellus, 51A, 951-963, 1999.

Dörnbrack, A., M. Leutbecher: Relevance of mountain waves for the formation of polar stratospheric clouds over Scandinavia: A 20 year climatology. $J$. Geophys. Res., 106, 1583-1594, 2001.

Dörnbrack, A., M. Leutbecher, J. Reichardt, A. Behrendt, K. P. Müller, G. Baumgarten: Relevance of 
mountain wave cooling for the formation of polar stratospheric clouds over Scandinavia: Mesoscale dynamics and observations for January 1997. J. Geo-phys. Res., 106, 1569-1582, 2001.

Hanson, D. R. , K. Mauersberger: Laboratory studies of the nitric acid trihydrate: implications for the south polar stratosphere. Geophys. Res. Let., 15, 855-858, 1988.

Kivi, R., E. Kyrö, A. Dörnbrack, T. Birner: Observations of vertically thick polar stratospheric clouds and record low temperature in the Arctic vortex. Geophys. Res. Let., 28, 3661-3664, 2001.

Koop, T., K. S. Carslaw, T. Peter: Thermodynamic stability and phase transitions of PSC particles. Geophys. Res. Let., 24, 2199-2202, 1997.

Lahoz, W. A., A. O’Neill, E. S. Carr, R. S. Harwood, L. Froidevaux, W. G. Read, J. W. Waters, J. B. Kumer, J. L. Mergenthaler, A. E. Roche, G. E. Peckham, R. Swinbank: Three-dimensional evolution of water vapor distributions in the Northern hemisphere stratosphere as observed by the MLS. J. Atmos. Sci., 51, 2914-2930, 1994.

Manney, G. L., H. A. Michelsen, M. L. Santee, M. R. Gunson, F. W. Irion, A. E. Roche, N. J. Livesey: Polar vortex dynamics during spring and fall diagnosed using trace gas observations from the Atmospheric Trace Molecule Spectroscopy instrument. J. Geophys. Res., 104, 18841-18866, 1999.

Marti, J., K. Mauersberger: A survey and new measurements of ice vapor pressure at temperature between 170 and 250 K. Geophys. Res. Let., 20, 363-366, 1993.

Ovarlez, J., H.Ovarlez: Stratospheric water vapor content evolution during EASOE. Geophys. Res. Let., 21, 1235-1238, 1994.

Pierce, R. B., T. D. Fairlie, W. L. Grose, R. Swinbank, A. O'Neill: Mixing processes within the polar night jet. J. Atmos. Sci., 51, 2957-2972, 1994.

Rex, M., K. Dethloff, D. Handorf, A. Herber, R. Lehmann, R. Neuber, J. Notholt, A. Rinke, P. von der Gathen, A. Weisheimer, H. Gernandt: Arctic and Antarctic ozone layer observations: chemical and dynamical aspects of variability and long-term changes in the polar stratosphere. Polar Res., 19, 193-204, 2000.

Schreiner, J., C. Voigt, A. Kohlmann, F. Arnold, K. Mauersberger, N. Larsen: Chemical analysis of polar stratospheric cloud particles. Science, 283, 968-970, 1999.

Seele, C., P. Hartogh: A case study on middle atmospheric water vapor transport during the February 1998 stratospheric warming. Geophys. Res. Let., 27, 3309-3312, 2000.

Shibata, T., K. Shiraishi, H. Adachi, Y. Iwasaka, M. Fujiwara: On the lidar-observed sandwich structure of polar stratospheric clouds (PSCs), 1. Implications for the mixing state of the PSC particles. J. Geophys. Res., 104, 21603-21611, 1999.

Solomon, S.: Stratospheric ozone depletion: A review of concepts and history. Rev. Geophys., 37, 275-316, 1999.
Stein, B., et al.: Optical classification, existence temperatures, and coexistence of different polar stratospheric cloud types. J. Geophys. Res., 104, 23983-23993, 1999.

Stowasser, M., H. Oelhaf, G. Wetzel, F. Friedl-Vallon, G. Maucher, M. Seefeldner, O. Trueschmann, T. v. Clarmann, H. Fischer: Simultaneous measurements of $\mathrm{HDO}, \mathrm{H}_{2} \mathrm{O}$, and $\mathrm{CH}_{4}$ with MIPAS-B: Hydrogen budget and indication of dehydration inside the polar vortex. J. Geophys. Res., 104, 19213-19225, 1999.

Tabazadeh, A., E. J. Jensen, O. B. Toon, K. Drdla, M. R. Schoeberl: Role of the stratospheric polar freezing belt in denitrification. Science, 291, 2591-2594, 2001.

Vömel, H., M. Rummukainen, R. Kivi, J. Karhu, T. Turunen, E. Kyrö, J. Rosen, N. Kjome, S. Oltmans: Dehydration and sedimentation of ice particles in the Arctic stratospheric vortex. Geophys. Res. Let., 24, 795-798, 1997.

Voigt, C., et al.: Nitric acid trihydrate (NAT) in polar stratospheric clouds. Science, 290, 1756-1758, 2000.

\footnotetext{
${ }^{1}$ now at Geoforschungszentrum Potsdam, Potsdam, Germany
} 